\title{
Gender differences in patients undergoing surgery for acute type A aortic dissection
}

\author{
Toshihiro Fukui, MD, ${ }^{a}$ Minoru Tabata, MD, MPH, ${ }^{\mathrm{a}, \mathrm{b}}$ Satoshi Morita, $\mathrm{PhD},{ }^{\mathrm{c}}$ and Shuichiro Takanashi, $\mathrm{MD}^{\mathrm{a}}$
}

\section{ABSTRACT}

Objectives: The impact of gender on preoperative characteristics and postoperative outcomes in patients undergoing surgery for acute type A aortic dissection rarely has been investigated.

Methods: We reviewed the records of 504 patients (245 women and 259 men) who underwent surgery for acute type A aortic dissection between August 2006 and December 2013. Women were older (71.5 vs 59.7 years; $P<.001)$ and smaller (body surface area 1.5 vs $1.9 \mathrm{~m}^{2} ; P<.001$ ) than men. Early and long-term outcomes were compared between men and women.

Results: Operative mortality ( $<30$ days) was similar between the groups $(4.5 \%$ vs $5.8 \% ; P=.646)$. Multivariable logistic regression analysis demonstrated that myocardial ischemia (odds ratio [OR], 5.48; 95\% confidence interval [CI], 2.00$15.00 ; P<.001)$, neurologic ischemia (OR, 6.64; 95\% CI, 2.26-19.48; $P<.001)$, and shock/tamponade (OR, 3.74; 95\% CI, 1.49-9.40; $P=.005)$ were independent predictors of operative mortality. At 5 years, there was no significant difference in survival between the groups $(80.1 \%$ vs $89.3 \% ; P=.067)$. Cox regression analysis demonstrated that myocardial ischemia (hazard ratio [HR], 2.40; 95\% CI, 1.21-4.74; $P=.012)$, nonprescription of beta-blockers at discharge (HR, 4.27; 95\% CI, 2.43-7.50; $P<.001$ ), and nonprescription of angiotensin II receptor blockers at discharge (HR, 2.39; 95\% CI, 1.14-5.01; $P=.021)$ were independent predictors of late mortality. Female gender was not an independent predictor of operative and late mortality.

Conclusions: There are no differences in early and long-term outcomes between male and female patients undergoing surgery for acute type A aortic dissection. (J Thorac Cardiovasc Surg 2015;150:581-7)

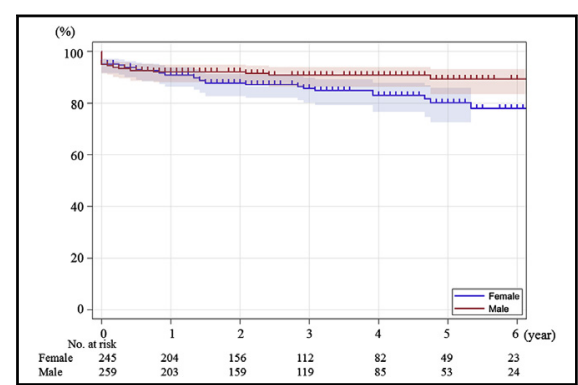

Kaplan-Meier event-free survival analysis for allcause mortality

Central Message

There are no differences in early and long-term outcomes between male and female patients undergoing surgery for AAAD.

\section{Perspective}

Female sex generally has been thought to be a risk factor in cardiac surgery, which may cause undertreatment of female patients with acute aortic dissection. Our study showed no impact of gender on the early and long-term outcomes after surgical repair for AAAD. This finding will promote adequate treatment in female patients with acute aortic dissection.

See Editorial Commentary page 587
Supplemental material is available online.

Gender difference in postoperative outcomes after cardiovascular surgery has been a matter of debate. In particular, the impact of female gender on clinical outcomes after isolated coronary artery bypass grafting $(\mathrm{CABG})$ has been well reported in multiple studies. Alam and colleagues ${ }^{1}$ demonstrated in their metaanalysis that women who underwent isolated $\mathrm{CABG}$

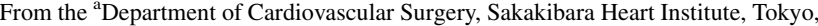
Japan; 'bepartment of Cardiovascular Surgery, Tokyo Bay Urayasu Ichikawa Medical Center, Chiba, Japan; and ${ }^{\mathrm{c}}$ Department of Biomedical Statistics and Bioinformatics, Kyoto University Graduate School of Medicine, Kyoto, Japan.

Received for publication Oct 8, 2014; revisions received May 25, 2015; accepted for publication June 5, 2015; available ahead of print July 16, 2015.
}

experienced higher mortality at short-, mid-, and longterm follow-up compared with men. In the risk models of both the Society of Thoracic Surgeons and the European System for Cardiac Operative Risk Evaluation, female gender is listed as one of the risk factors for cardiac surgery. ${ }^{2,3}$ Several reasons for a worse outcome in female patients have been proposed. ${ }^{4-13}$ Female patients who undergo $\mathrm{CABG}$ are generally older and smaller than their male counterparts. Female patients also have more preoperative comorbidities, such as diabetes and anemia.

\footnotetext{
Address for reprints: Toshihiro Fukui, MD, Department of Cardiovascular Surgery, Sakakibara Heart Institute, 3-16-1 Asahi-cho, Fuchu-shi, Tokyo 183-0003, Japan (E-mail: tfukui.cvs@gmail.com).

$0022-5223 / \$ 36.00$

Copyright () 2015 by The American Association for Thoracic Surgery http://dx.doi.org/10.1016/j.jtcvs.2015.06.031
} 


$$
\begin{aligned}
\text { Abbreviations and Acronyms } \\
\text { AAAD }=\text { acute type A aortic dissection } \\
\text { CABG }=\text { coronary artery bypass grafting } \\
\text { CI }=\text { confidence interval } \\
\text { CT }=\text { computed tomography } \\
\text { HR }=\text { hazard ratio } \\
\text { IRAD }=\text { International Registry of Acute Aortic } \\
\text { Dissection } \\
\text { OR }=\text { odds ratio } \\
\text { TAR }=\text { total arch replacement }
\end{aligned}
$$

Acute type A aortic dissection (AAAD) is one of the leading causes of death in both men and women. There have been few published reports regarding gender difference in postoperative outcomes after surgical repair of AAAD. The aim of this study was to compare the early and long-term outcomes in adult male and female patients after repair of AAAD.

\section{PATIENTS AND METHODS Study Patients}

Between August 2006 and December 2013, 504 patients underwent surgical repair for AAAD at the Sakakibara Heart Institute. The preoperative characteristics of these patients are shown in Table 1. There were 245 women and 259 men. The mean age of female patients was significantly higher than that of male patients ( 71.5 vs 59.7 years; $P<.0001)$. Female patients were significantly smaller than their male counterparts (body surface area $\left.1.5 \mathrm{vs} 1.9 \mathrm{~m}^{2} ; P<.0001\right)$. The level of creatinine was higher in male patients than in female patients ( $0.9 \mathrm{vs} 1.2 \mathrm{mg} / \mathrm{dL} ; P=.0017)$; however, the estimated glomerular filtration rate was not different between the groups (61.1 vs $\left.61.4 \mathrm{~mL} / \mathrm{min} / 1.73 \mathrm{~m}^{2} ; P=.8921\right)$. Other risk factors were almost identical between the groups. Intervals from symptom onset to operation and the rate of early operation (within 6 hours) did not differ between the groups.

The primary end point of this study was operative mortality, and the secondary end points were late mortality and late reoperation. The indications for AAAD-related reoperation were rupture or impending rupture of aorta, dilatation of aorta $55 \mathrm{~mm}$ or greater, rapid dilatation of aorta more than 10 $\mathrm{mm}$ per year, graft infection, and severe aortic valve insufficiency. Computed tomography (CT) studies were obtained before discharge, 6 months after surgery, and annually thereafter.

The institutional review board approved this retrospective study and waived the need for written consent. We followed up patients by outpatient clinic visits or telephone interview in March and April of 2014.

\section{Operations}

All operations were performed through a median sternotomy; the initial arterial cannula was placed mostly in the femoral artery. The left ventricular apex or axillary artery was cannulated if the femoral artery was unavailable. Our strategy of selection of the cannulation site has been described. ${ }^{14}$ In all patients, a combination of antegrade and retrograde cardioplegia was used, and patients were cooled to $25^{\circ} \mathrm{C}$ for circulatory arrest. A singlebranch prosthesis was used in ascending aortic or hemiarch replacement, and a 4-branch prosthesis was used in total arch replacement (TAR). The proximal aorta was repaired with gelatin resorcinol formaldehyde glue and double strips (vascular graft strip inside and Teflon felt strip outside) at the level of the sinotubular junction. When there was an intimal tear in the aortic root or the aortic root was dilated, the aortic root was replaced without using glue. In patients undergoing ascending aortic or hemiarch replacement, the distal aortic repair and anastomosis were performed under hypothermic circulatory arrest with retrograde cerebral perfusion from the superior vena cava. The distal aorta was repaired with double Teflon felt strips and then anastomosed to the vascular graft. After the distal anastomosis, whole-body circulation was resumed through the branch of the prosthesis, and the patient was fully rewarmed to $35^{\circ} \mathrm{C}$. Proximal anastomosis was performed during rewarming. In patients undergoing TAR, we introduced the stepwise distal anastomosis technique with antegrade selective cerebral perfusion and separate lower body perfusion. ${ }^{15}$ The details of our current TAR techniques have been reported. ${ }^{15}$ Four surgeons performed the operations throughout this study period.

\section{Definitions}

Intramural hematoma was defined as a dissecting membrane without any degree of patency of the false lumen. Cerebrovascular accident was defined as the persistent loss of neurologic function caused by an ischemic event, with or without confirmation by CT or magnetic resonance imaging. Cardiac tamponade was defined as a cardiogenic shock with a systolic blood pressure of $90 \mathrm{~mm} \mathrm{Hg}$, associated with pericardial effusion confirmed by CT or echocardiography. Operative mortality was defined as death within 30 days after surgery or before discharge. Postoperative stroke was defined as the occurrence of a new stroke confirmed by CT. In patients with preoperative stroke, postoperative stroke was defined as worsening of the neurologic deficit with new radiologic findings.

\section{Statistical Analysis}

The study by Nienaber and colleagues ${ }^{16}$ demonstrated that the difference regarding operative death between genders was $10 \%$. Given the sample size of 500 in total, the statistical powers to detect the group difference of $10 \%$ were calculated to be $85 \%, 76 \%$, and $69 \%$ when incidence rates of a control arm were $10 \%, 15 \%$, and $20 \%$, respectively, with a type I error of $5 \%$ (2sided). By accounting for such a variability in the incidence rate for a between-group comparison, we set the sample size of the present study at 500 .

All statistical analyses were performed using the StatView 5.0 software package or the SAS program for Windows, release 9.2 (SAS Institute Inc, Cary, NC). Continuous variables are reported as the mean \pm standard deviation. Continuous variables were compared using the Student $t$ - test, and discrete variables were compared using the chi-square test or Fisher exact test.

Univariate and multivariate logistic regression analyses were performed to determine the significant predictors of operative mortality. The variables used for univariate analysis were the clinical variables listed in Table 1, in addition to female and male gender. Variables identified as having a $P$ value of less than .1 on univariate analyses were considered for inclusion in the multivariate model.

Actuarial event-free survival curves were estimated by the Kaplan-Meier method. The log-rank test was used to assess differences in survival between groups.

Univariate and multivariate Cox proportional hazard analyses were performed to investigate the significant predictors of late mortality and reoperation. The variables compared in the univariate analysis are listed in Table 1. Variables with a $P$ value less than .1 on univariate analyses were included in the multivariate model.

\section{RESULTS \\ Early Outcomes}

The operative data are listed in Table 2. TAR (19.2\% vs $44.8 \% ; P<.0001)$ and aortic root replacement $(9.0 \%$ vs $19.7 \% ; P=.0010)$ were performed less frequently in women than in men. Consequently, operation time (232.0 vs 273.4 minutes; $P<.0001)$ and aortic crossclamp time (91.4 vs 118.0 minutes; $P<.0001)$ were shorter for female 
TABLE 1. Preoperative variables

\begin{tabular}{|c|c|c|c|c|}
\hline & All & Female & Male & \\
\hline Number & 504 & 245 & 259 & value \\
\hline Age & $65.3 \pm 13.3$ & $71.5 \pm 9.8$ & $59.7 \pm 13.4$ & $<.0001$ \\
\hline$\geq 70 \mathrm{y}$ & $218(43.3 \%)$ & $155(63.3 \%)$ & $63(24.3 \%)$ & $<.0001$ \\
\hline $\begin{array}{c}\text { Body surface } \\
\text { area }\left(\mathrm{m}^{2}\right)\end{array}$ & $1.7 \pm 0.9$ & $1.5 \pm 0.1$ & $1.9 \pm 1.2$ & $<.0001$ \\
\hline DeBakey type I & $342(67.9 \%)$ & $167(68.2 \%)$ & $175(67.6 \%)$ & .9619 \\
\hline type II & $70(13.9 \%)$ & $45(18.4 \%)$ & $25(9.7 \%)$ & .0070 \\
\hline type III r & $92(18.3 \%)$ & $33(13.5 \%)$ & $59(22.8 \%)$ & .0096 \\
\hline Intramural hematoma & $101(20.0 \%)$ & $56(22.9 \%)$ & $45(17.4 \%)$ & .1540 \\
\hline Hypertension & $437(86.7 \%)$ & $210(85.7 \%)$ & $227(87.6 \%)$ & .6123 \\
\hline Diabetes mellitus & $31(6.2 \%)$ & $14(5.7 \%)$ & $17(6.6 \%)$ & .8327 \\
\hline Hyperlipidemia & $107(21.2 \%)$ & $47(19.2 \%)$ & $60(23.2 \%)$ & .3252 \\
\hline Marfan syndrome & $11(2.2 \%)$ & $5(2.0 \%)$ & $6(2.3 \%)$ & $>.9999$ \\
\hline Myocardial ischemia & $40(7.9 \%)$ & $17(6.9 \%)$ & $23(8.9 \%)$ & .5215 \\
\hline Brain ischemia & $28(5.6 \%)$ & $17(6.9 \%)$ & $11(4.3 \%)$ & .2610 \\
\hline Shock/tamponade & $121(24.0 \%)$ & $68(27.8 \%)$ & $53(20.5 \%)$ & .0701 \\
\hline Shock & $85(16.9 \%)$ & $48(19.6 \%)$ & $37(14.3 \%)$ & .1413 \\
\hline Tamponade & $95(18.8 \%)$ & $52(22.4 \%)$ & $40(15.4 \%)$ & .0580 \\
\hline $\begin{array}{l}\text { Aortic regurgitation } \\
\text { grade } 3 \text { or } 4\end{array}$ & $60(11.9 \%)$ & $23(9.4 \%)$ & $37(14.3 \%)$ & .1189 \\
\hline Creatinine $(\mathrm{mg} / \mathrm{dL})$ & $1.0 \pm 1.1$ & $0.9 \pm 0.9$ & $1.2 \pm 1.2$ & .0017 \\
\hline $\begin{array}{l}\text { eGFR } \\
\qquad\left(\mathrm{mL} / \mathrm{min} / 1.73 \mathrm{~m}^{2}\right)\end{array}$ & $61.2 \pm 21.9$ & $61.1 \pm 22.6$ & $61.4 \pm 21.4$ & .8921 \\
\hline $\begin{array}{l}\text { Hours from symptom } \\
\text { onset to operation }\end{array}$ & $67.4 \pm 245.4$ & $69.2 \pm 297.5$ & $65.7 \pm 183.7$ & .8761 \\
\hline Within $6 \mathrm{~h}$ & $239(47.4 \%)$ & $114(46.5 \%)$ & $125(48.3 \%)$ & .7642 \\
\hline $\begin{array}{l}\text { The first half of } \\
\text { the cohort }\end{array}$ & $252(50 \%)$ & $128(52.2 \%)$ & $124(47.9 \%)$ & .3728 \\
\hline
\end{tabular}

patients. The frequency of other procedures was almost identical between the groups. The length of stay in the intensive care unit was not different between the genders (3.2 vs 3.5 days; $P=.5440$ ).

Postoperative outcomes are listed in Table 2. The operative mortality was not different between the groups $(4.5 \%$ vs $5.8 \% ; P=.6463)$. Causes of death in women were stroke in 4 patients, mesenteric ischemia in 3 patients, myocardial infarction in 2 patients, and multiorgan failure in 2 patients. Causes of death in men were multiorgan failure in 6 patients, stroke in 5 patients, myocardial infarction in 3 patients, and pneumonia in 1 patient. There was no significant difference in operative mortality between patients who underwent complex procedures (total arch or root replacement) and those who did not $(6.0 \%$ vs $6.7 \% ; P>.9999)$. Furthermore, there was no significant difference in operative mortality between elderly patients (aged $\geq 70$ years) and young patients $(5.8 \%$ vs $4.8 \% ; P>$.9999) (Table E1). Moreover, the incidences of postoperative major complications were not significantly different between the genders. Although prevalence of medications at discharge was not significantly different between the groups, the frequency of prescribed beta-blockers tended to be higher for men.
TABLE 2. Operative and postoperative data

\begin{tabular}{|c|c|c|c|c|}
\hline & All & Female & Male & $\begin{array}{c}P \\
\text { value }\end{array}$ \\
\hline TAR & $163(32.3 \%)$ & $47(19.2 \%)$ & $116(44.8 \%)$ & $<.0001$ \\
\hline $\begin{array}{l}\text { Aortic root } \\
\text { replacement }\end{array}$ & $73(14.5 \%)$ & $22(9.0 \%)$ & $51(19.7 \%)$ & .0010 \\
\hline $\begin{array}{l}\text { Total arch and/or root } \\
\text { replacement }\end{array}$ & $216(42.9 \%)$ & $67(27.3 \%)$ & $149(57.5 \%)$ & $<.0001$ \\
\hline CABG & $46(9.1 \%)$ & $19(7.8 \%)$ & $27(10.4 \%)$ & .3759 \\
\hline $\begin{array}{l}\text { Aortic valve repair or } \\
\text { replacement }\end{array}$ & $73(14.5 \%)$ & $29(11.8 \%)$ & $44(17.0 \%)$ & .1296 \\
\hline $\begin{array}{l}\text { Femoro-femoral } \\
\text { bypass }\end{array}$ & $17(3.4 \%)$ & $7(2.9 \%)$ & $10(3.9 \%)$ & .7061 \\
\hline Operation time (min) & $253.3 \pm 80.8$ & $232.0 \pm 71.6$ & $273.4 \pm 83.9$ & $<.0001$ \\
\hline $\begin{array}{l}\text { Aortic crossclamp } \\
\text { time (min) }\end{array}$ & $105.1 \pm 50.3$ & $91.4 \pm 42.6$ & $118.0 \pm 53.5$ & $<.0001$ \\
\hline $\begin{array}{l}\text { Intensive care unit } \\
\text { stay (d) }\end{array}$ & $3.4 \pm 4.7$ & $3.2 \pm 4.1$ & $3.5 \pm 5.2$ & .5440 \\
\hline $\begin{array}{l}\text { Operative mortality } \\
\qquad(<30 \mathrm{~d})\end{array}$ & $26(5.2 \%)$ & $11(4.5 \%)$ & $15(5.8 \%)$ & .6463 \\
\hline Stroke & $70(13.9 \%)$ & $33(13.5 \%)$ & $37(14.3 \%)$ & .8918 \\
\hline $\begin{array}{l}\text { Renal failure } \\
\text { requiring } \\
\text { hemodialysis }\end{array}$ & $42(8.3 \%)$ & $22(9.0 \%)$ & $20(7.7 \%)$ & .7268 \\
\hline Mesenteric ischemia & $3(0.6 \%)$ & $2(0.8 \%)$ & $1(0.4 \%)$ & .6141 \\
\hline Limb ischemia & $2(0.4 \%)$ & $1(0.4 \%)$ & $1(0.4 \%)$ & $>.9999$ \\
\hline Mediastinitis & $16(3.2 \%)$ & $5(2.0 \%)$ & $11(4.2 \%)$ & .2056 \\
\hline \multicolumn{5}{|l|}{$\begin{array}{r}\text { Medication at } \\
\text { discharge }\end{array}$} \\
\hline Aspirin & $100(19.8 \%)$ & $44(18.0 \%)$ & $56(21.6 \%)$ & .3582 \\
\hline Beta-blocker & $407(80.8 \%)$ & $189(77.1 \%)$ & $218(84.2 \%)$ & .0592 \\
\hline $\begin{array}{l}\text { Angiotensin II } \\
\text { receptor blocker }\end{array}$ & $244(48.4 \%)$ & $116(47.3 \%)$ & $128(49.4 \%)$ & .7066 \\
\hline ACE inhibitor & $20(4.0 \%)$ & $8(3.3 \%)$ & $12(4.6 \%)$ & .3385 \\
\hline $\begin{array}{l}\text { Calcium-channel } \\
\text { blocker }\end{array}$ & $286(56.7 \%)$ & $133(54.3 \%)$ & $153(59.1 \%)$ & .3200 \\
\hline Statin & $64(12.7 \%)$ & $25(10.2 \%)$ & $39(15.1 \%)$ & .1331 \\
\hline
\end{tabular}

$A C E$, Angiotensin-converting enzyme; $C A B G$, coronary artery bypass grafting; TAR, total arch replacement.

\section{Predictors of Operative Mortality}

In univariate analysis, hypertension $(P=.0418)$, myocardial ischemia $(P<.0001)$, brain ischemia $(P<.0001)$, and shock $/$ tamponade $(P<.0001)$ were selected for further multivariate analysis. Multivariable logistic regression analysis (Table 3) demonstrated that myocardial ischemia $(P=.0009)$, brain ischemia $(P=.0006)$, and shock/tamponade $(P=.0051)$

TABLE 3. Multivariate logistic regression analyses for operative mortality

\begin{tabular}{lccc}
\hline \multicolumn{1}{c}{ Variable } & OR & $\boldsymbol{P}$ value & \multicolumn{1}{c}{$\mathbf{9 5 \%}$ CI } \\
\hline Female & 0.703 & .4485 & $0.283-1.748$ \\
Hypertension & 0.401 & .0830 & $0.143-1.127$ \\
Myocardial ischemia & 5.475 & .0009 & $1.998-15.000$ \\
Brain ischemia & 6.640 & .0006 & $2.263-19.482$ \\
Shock/tamponade & 3.738 & .0051 & $1.487-9.400$ \\
\hline
\end{tabular}

CI, Confidence interval; OR, odds ratio. 

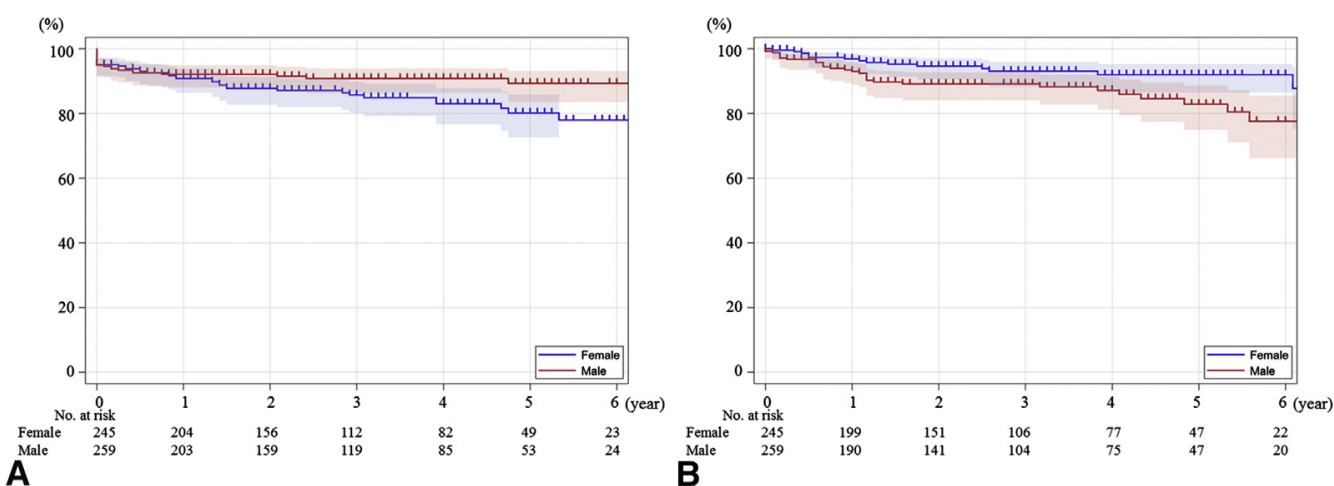

FIGURE 1. A, Kaplan-Meier event-free survival analysis for all-cause mortality. B, Kaplan-Meier event-free survival analysis for reoperation.

were independent predictors of operative mortality, whereas female gender was not.

\section{Long-Term Outcome}

Follow-up was completed in 495 of 504 patients $(98.2 \%)$. There was no difference in the follow-up rate by gender $(P=.7457)$. During the follow-up period $(35.5 \pm 24.9$ months), there were 38 deaths $(15.5 \%)$ in female patients and 24 deaths $(9.3 \%)$ in male patients. The actuarial survival at 5 years was $80.1 \% \pm 3.4 \%$ in female patients and $89.3 \%$ $\pm 2.4 \%$ in male patients (Figure $1, A$ ). At 5 years, there was no significant difference in survival between the groups $(P=.0665)$. There was no significant difference in survival between patients who underwent complex procedures (total arch or root replacement) and patients who did not $(71.6 \% \pm$ $8.6 \%$ vs $88.1 \% \pm 3.3 \% ; P=.1175)$.

There were 16 reoperations $(6.5 \%)$ in female patients and 31 reoperations $(12.0 \%)$ in male patients during a follow-up period. In female patients, there were 14 distal and 2 proximal operations. In male patients, there were 25 distal and 6 proximal operations. The actuarial rate of freedom from reoperation at 5 years was $92.0 \% \pm 2.2 \%$ in female patients and $82.9 \% \pm 3.4 \%$ in male patients (Figure 1, B). At 5 years, the rate of freedom from reoperation was significantly higher in female patients than in male patients $(P=.0239)$. In the subgroup of patients who underwent complex procedures, the rate of freedom from reoperation was also significantly higher in female patients than in male patients $(98.2 \% \pm 1.8 \%$ vs $80.2 \% \pm 4.7 \%$; $P=$.0045).

\section{Predictors of Late Mortality}

In univariate analysis, female gender $(P=.0556)$, older age $(P=.0004)$, smaller body surface area $(P=.0134)$, absence of hypertension $(P=.0012)$, myocardial ischemia $(P<.0001)$, brain ischemia $(P<.0001)$, shock/tamponade $(P=.0008)$, nonprescription of $\beta$-blocker at discharge $(P<.0001)$, nonprescription of angiotensin II receptor blocker at discharge $(P<.0001)$, and nonprescription of calcium channel blocker at discharge $(P=.0002)$ were selected for further multivariate analysis.
Multivariable Cox regression analysis (Table 4) demonstrated that myocardial ischemia $(P=.0121)$, nonprescription of beta-blocker at discharge $(P<.0001)$, nonprescription of angiotensin II receptor blocker at discharge $(P=.0214)$, and the first half of the cohort $(P=.0242)$ were independent predictors of late mortality, whereas female gender was not.

\section{Predictors of Late Reoperation}

In univariate analysis, male gender $(P=.0187)$, younger age $(P=.0106)$, Marfan syndrome $(P=.0890)$, and nonprescription of beta-blocker at discharge $(P=.0213)$ were selected for further multivariate analysis.

Multivariable Cox regression analysis demonstrated that only nonprescription of beta-blocker at discharge (hazard ratio, 2.398, 95\% confidence interval, 1.262-4.558; $P=.0076)$ was an independent predictor of late reoperation. Female gender was not an independent predictor of late reoperation.

\section{DISCUSSION}

Acute aortic dissection is one of the major leading causes of death in cardiovascular disease. Because surgical treatment has been the standard therapy for AAAD, predictors

TABLE 4. Multivariate Cox regression analyses for late mortality

\begin{tabular}{lccc}
\hline \multicolumn{1}{c}{ Variable } & HR & $\boldsymbol{P}$ value & $\mathbf{9 5 \%}$ CI \\
\hline Female & 0.957 & .9045 & $0.453-1.976$ \\
Older age & 1.023 & .1103 & $1.597-2.550$ \\
Body surface area & 0.873 & .8819 & $0.146-5.209$ \\
Hypertension & 0.801 & .4996 & $0.421-1.524$ \\
Myocardial ischemia & 2.410 & .0121 & $1.212-4.785$ \\
Brain ischemia & 1.466 & .3260 & $0.684-3.145$ \\
Shock/tamponade & 1.316 & .3381 & $0.750-2.309$ \\
Nonprescription of beta-blocker at discharge & 4.372 & $<.0001$ & $2.477-7.717$ \\
Nonprescription of angiotensin II receptor & 2.564 & .0127 & $1.223-5.376$ \\
$\quad$ blocker at discharge & & & \\
Nonprescription of calcium channel blocker & 1.316 & .3810 & $0.712-2.435$ \\
$\quad$ at discharge & & & \\
The first half of the cohort & 1.961 & .0242 & $1.092-3.521$ \\
\hline CI, Confidence interval; $H R$, hazard ratio. & & &
\end{tabular}


of postoperative outcomes have been of great concern. Gender-related difference in patients undergoing repair of AAAD also should be of interest, because understanding gender differences in outcomes after repair of AAAD has important public health implications. In the present study, no gender difference was demonstrated with regard to early and long-term mortality and late reoperation after surgical repair for AAAD.

Although gender-related difference in patients undergoing $\mathrm{CABG}$ has been well investigated, there have been few reports regarding such differences in patients undergoing surgical repair of AAAD, one reason for which may be that the number of patients undergoing repair of AAAD in a single institute is limited in Western countries. There is only one study dealing with gender-related differences in patients undergoing surgical repair of AAAD using data from the International Registry of Acute Aortic Dissection $(\mathrm{IRAD})^{16}$; however, because this was a multicenter study, the surgical teams involved and the methods used were not uniform. By contrast, operations in the present study were performed in a single center and the surgical method was uniform, although 4 surgeons were included. According to the survey by the Japanese Association for Thoracic Surgery, operative mortality has steadily decreased from $22 \%$ to $10 \%$ since 1997 through $2012 .{ }^{17}$ However, there has been no study dealing with gender-related differences in patients undergoing surgical repair of AAAD using data from the Japanese Association for Thoracic Surgery.

In the present study, female patients less frequently underwent complex surgery than male patients. We selected a procedure on the basis of the preoperative clinical status, the location of the intimal tear, or the size of the aorta, and we did not change procedures by gender. A difference in age between male and female patients may have influenced our procedure selection. Reports from IRAD investigators demonstrated that younger patients underwent more root surgery and aortic arch surgery compared with older patients. ${ }^{18,19}$

Nienaber and colleagues ${ }^{16}$ demonstrated that surgical outcomes in patients with AAAD were worse in women (mortality $31.9 \%$ ) than in men (mortality $21.9 \%$ ). They further suggested that this was because of a later diagnosis and a critical preoperative condition in women; late diagnosis worsens patients' prognosis. In their analysis, women were older, and more women had hypertension, congestive heart failure, coronary artery compromise, and pericardial effusion. In the present study, multivariate analysis demonstrated that age and female gender were not independent predictors of operative mortality. However, serious conditions preoperatively, including myocardial ischemia, brain ischemia, and shock/tamponade, were independent predictors of operative mortality. These findings were almost equivalent to the results of another study of IRAD. ${ }^{20}$ It is easy to surmise that these critical conditions may affect the postoperative outcome. Although the prevalence of these conditions was not significantly different between the genders, only shock/tamponade tended to be more frequent in female patients $(27.8 \%$ vs $20.5 \%)$ in the present study. Cardiac tamponade is a known predictor of early death in patients with AAAD. ${ }^{21}$ According to the IRAD analysis, cardiac tamponade was observed more frequently in women than in men. ${ }^{21}$ Although the reason for this is not clear, it is possible that even a small amount of hemorrhage in the pericardial cavity may lead to a serious effect on hemodynamics because women have a smaller body surface area.

In the present study, female patients undergoing repair of AAAD were older than male patients, which is also typical of other cardiovascular diseases. The results of the IRAD analysis showed that aortic dissection occurs in women on average 6 or 7 years later than in men. ${ }^{16}$ This is partly because, compared with male patients, female patients do not experience cardiac disease until the onset of menopause, presumably because of the protective effects of estrogen on the cardiovascular system. ${ }^{9}$ Age was not an independent predictor of operative mortality in the present study. Historically, age has been a risk factor for death after surgery for AAAD. ${ }^{2,23}$ Elderly patients with AAAD have more comorbidity and a more fragile aorta than nonelderly patients. However, we did not find that emergency open surgery for AAAD in elderly patients resulted in high mortality, ${ }^{24}$ perhaps because of our high surgical volume and established efficient process of diagnosis and treatment in a single institute. Mehta and colleagues ${ }^{20}$ pointed out that an aggressive and early surgical treatment is the only option to provide a reasonable chance of survival and prevent many complications.

Long-term survival has been reported to be $45 \%$ to $88 \%$ at 5 years and $30 \%$ to $60 \%$ at 10 years. ${ }^{25,26}$ Some investigators have reported predictors of late mortality in patients undergoing repair of AAAD. Bekkers and colleagues $^{27}$ demonstrated that age, prior myocardial infarction, preoperative creatinine level, chronic pulmonary obstructive disease, and poor left ventricular function were independent predictors of late mortality. Zierer and colleagues $^{28}$ found that earlier operative year, age, female gender, chronic renal insufficiency, and coronary artery disease were the independent predictors. In the present study, female gender was not an independent predictor of late mortality by multivariate analysis, although there was a tendency toward a statistically significant difference by Kaplan-Meier analysis. However, as in other studies, preoperative myocardial ischemia was associated with late mortality. Coronary involvement in patients with AAAD is a critical condition with a high in-hospital mortality rate. ${ }^{29}$ Furthermore, it also affects the long-term prognosis even after a successful operation. ${ }^{29}$ Emergency percutaneous coronary intervention before surgical repair of 
AAAD may be a lifesaving approach in patients with myocardial ischemia.

To prevent late adverse events, follow-up with appropriate medication is essential for patients who have undergone surgery for AAAD. Current guidelines for the management of patients with thoracic aortic disease recommend the use of beta-blockers, angiotensin-converting enzyme inhibitors, and angiotensin receptor blockers to reduce blood pressure for patients with thoracic aortic aneurysm. By using the IRAD database, Suzuki and colleagues ${ }^{30}$ demonstrated that the use of beta-blockers was associated with improved survival in patients with AAAD who underwent surgery (odds ratio $0.47,95 \%$ confidence interval, $0.25-0.90, P=.02)$. Melby and colleagues ${ }^{31}$ demonstrated that reoperation was markedly decreased in patients receiving beta-blocker therapy after repair of AAAD, who also had improved blood pressure control at late followup. Beta-blockers are considered first-line medication in patients with AAAD because they effectively reduce blood pressure and heart rate. ${ }^{25}$ In line with other studies, the present study confirmed that beta-blockade was effective in improving late mortality and late reoperation rate after repair of AAAD. Furthermore, our study revealed the effectiveness of angiotensin II receptor blockers in improving late mortality after repair of AAAD. Their significant effect on reduction in the rate of change in aortic root diameter in patients with Marfan syndrome has been confirmed by a randomized trial. ${ }^{32}$ Another group showed the effectiveness of angiotensin II receptor blockers in reducing the rate of aortic arch dilatation in patients with Marfan syndrome who had prior aortic root replacement. ${ }^{33}$ Because few data are available regarding the effectiveness of angiotensin II receptor blockers in improving long-term adverse outcomes after repair of AAAD, further large, prospective studies are needed to confirm this possibility.

In the present study, male patients had a higher rate of reintervention during a follow-up period despite the fact that they had more complex procedures at the initial procedure and they were discharged more frequently on betablockers when compared with female patients. A difference in age between male and female patients may have influenced the incidence of reintervention in this study. Geirsson and colleagues ${ }^{34}$ demonstrated that younger age was one of the independent risk factors of distal reoperations.

There may be a histologic difference in the aortic wall tissue by gender, as Huynh and $\operatorname{Starr}^{35}$ described. In the present study, we did not perform histologic examination for the surgical specimen of acute aortic dissection.

\section{Study Limitations}

Because this is a retrospective observational study, there might be some bias that we did not adjust in the multivariate analyses. Also, the number of patients and the follow-up period of 5 years might not be sufficient to provide definitive results. Moreover, we did not have details on the reasons for nonprescribing the medications.

\section{CONCLUSIONS}

Our study demonstrated no significant differences in early and long-term outcomes between male and female patients undergoing surgery for AAAD. Further studies with larger samples and longer follow-up are needed.

\section{Conflict of Interest Statement}

Authors have nothing to disclose with regard to commercial support.

\section{References}

1. Alam M, Bandeali SJ, Kayani WT, Ahmad W, Shahzad SA, Jneid H, et al. Comparison by meta-analysis of mortality after isolated coronary artery bypass grafting in women versus men. Am J Cardiol. 2013;112:309-17.

2. Shroyer AL, Coombs LP, Peterson ED, Eiken MC, DeLong ER, Chen A, et al; Society of Thoracic Surgeons. The Society of Thoracic Surgeons: 30-day operative mortality and morbidity risk models. Ann Thorac Surg. 2003;75:1856-64.

3. Nashef SA, Roques F, Sharples LD, Nilsson J, Smith C, Goldstone AR, et al. EuroSCORE II. Eur J Cardiothorac Surg. 2012;41:734-44.

4. Fisher LD, Kennedy JW, Davis KB, Maynard C, Fritz JK, Kaiser G, et al. Association of sex, physical size, and operative mortality after coronary artery bypass in the Coronary Artery Surgery Study (CASS). J Thorac Cardiovasc Surg. 1982; 84:334-41.

5. Cosgrove DM, Loop FD, Lytle BW, Baillot R, Gill CC, Golding LA, et al. Primary myocardial revascularization. Trends in surgical mortality. J Thorac Cardiovasc Surg. 1984;88:673-84.

6. Hannan EL, Bernard HR, Kilburn HC Jr, O'Donnell JF. Gender differences in mortality rates for coronary artery bypass surgery. Am Heart J. 1992;123:866-72.

7. Weintraub WS, Wenger NK, Jones EL, Craver JM, Guyton RA. Changing clinical characteristics of coronary surgery patients. Differences between men and women. Circulation. 1993;88:II79-86.

8. Edwards FH, Carey JS, Grover FL, Bero JW, Hartz RS. Impact of gender on coronary bypass operative mortality. Ann Thorac Surg. 1998;66:125-31.

9. Hogue CW Jr, Barzilai B, Pieper KS, Coombs LP, DeLong ER, Kouchoukos NT, et al. Sex differences in neurological outcomes and mortality after cardiac surgery: a Society of Thoracic Surgery national database report. Circulation. 2001;103:2133-7.

10. Vaccarino V, Abramson JL, Veledar E, Weintraub WS. Sex differences in hospital mortality after coronary artery bypass surgery: evidence for a higher mortality in younger women. Circulation. 2002;105:1176-81.

11. Zitser-Gurevich Y, Simchen E, Galai N, Mandel M, ISCAB Consortium. Effect of perioperative complications on excess mortality among women after coronary artery bypass: the Israeli Coronary Artery Bypass Graft Study (ISCAB). J Thorac Cardiovasc Surg. 2002;123:517-24.

12. Guru V, Fremes SE, Tu JV. Time-related mortality for women after coronary artery bypass graft surgery: a population-based study. J Thorac Cardiovasc Surg. 2004; 127:1158-65.

13. Bukkapatnam RN, Yeo KK, Li Z, Amsterdam EA. Operative mortality in women and men undergoing coronary artery bypass grafting (from the California Coronary Artery Bypass Grafting Outcomes Reporting Program). Am J Cardiol. 2010; 105:339-42.

14. Shimokawa T, Takanashi S, Ozawa N, Itoh T. Management of intraoperative malperfusion syndrome using femoral artery cannulation for repair of acute type A aortic dissection. Ann Thorac Surg. 2008;85:1619-24.

15. Matsuyama S, Tabata M, Shimokawa T, Matsushita A, Fukui T, Takanashi S. Outcomes of total arch replacement with stepwise distal anastomosis technique and modified perfusion strategy. J Thorac Cardiovasc Surg. 2012;143:1377-81.

16. Nienaber CA, Fattori R, Mehta RH, Richartz BM, Evangelista A, Petzsch M, et al; International Registry of Acute Aortic Dissection. Gender-related differences in acute aortic dissection. Circulation. 2004;109:3014-21.

17. Okita Y. Surgery for thoracic aortic disease in Japan: evolving strategies toward the growing enemies. Gen Thorac Cardiovasc Surg. 2015;63:185-96.

18. Mehta RH, O'Gara PT, Bossone E, Nienaber CA, Myrmel T, Cooper JV, et al; International Registry of Acute Aortic Dissection (IRAD) Investigators. Acute 
type A aortic dissection in the elderly: clinical characteristics, management, and outcomes in the current era. J Am Coll Cardiol. 2002;40:685-92.

19. Januzzi JL, Isselbacher EM, Fattori R, Cooper JV, Smith DE, Fang J, et al; International Registry of Aortic Dissection (IRAD). Characterizing the young patient with aortic dissection: results from the International Registry of Aortic Dissection (IRAD). J Am Coll Cardiol. 2004:43:665-9.

20. Mehta RH, Suzuki T, Hagan PG, Bossone E, Gilon D, Llovet A, et al; International Registry of Acute Aortic Dissection (IRAD) Investigators. Predicting death in patients with acute type a aortic dissection. Circulation. 2002;105:200-6.

21. Gilon D, Mehta RH, Oh JK, Januzzi JL Jr, Bossone E, Cooper JV, et al; International Registry of Acute Aortic Dissection Group. Characteristics and in-hospital outcomes of patients with cardiac tamponade complicating type A acute aortic dissection. Am J Cardiol. 2009;103:1029-31.

22. Svensson LG, Crawford ES, Hess KR, Coselli JS, Safi HJ. Dissection of the aorta and dissecting aortic aneurysms. Improving early and long-term surgical results. Circulation. 1990;82(Suppl):IV24-38.

23. Ehrlich M, Fang WC, Grabenwöger M, Cartes-Zumelzu F, Wolner E, Havel M. Perioperative risk factors for mortality in patients with acute type A aortic dissection. Circulation. 1998;98(Suppl):II294-8.

24. Matsushita A, Tabata M, Fukui T, Sato Y, Matsuyama S, Shimokawa T, et al. Outcomes of contemporary emergency open surgery for type A acute aortic dissection in elderly patients. J Thorac Cardiovasc Surg. 2014;147:290-4.

25. Braverman AC. Acute aortic dissection: clinician update. Circulation. 2010;122: 184-8.

26. Krüger T, Conzelmann LO, Bonser RS, Borger MA, Czerny M, Wildhirt S, et al. Acute aortic dissection type A. Br J Surg. 2012;99:1331-44.

27. Bekkers JA, Raap GB, Takkenberg JJ, Bogers AJ. Acute type A aortic dissection: long-term results and reoperations. Eur J Cardiothorac Surg. 2013;43:389-96.
28. Zierer A, Voeller RK, Hill KE, Kouchoukos NT, Damiano RJ Jr, Moon MR Aortic enlargement and late reoperation after repair of acute type A aortic dissection. Ann Thorac Surg. 2007;84:479-86.

29. Kawahito K, Adachi H, Murata S, Yamaguchi A, Ino T. Coronary malperfusion due to type A aortic dissection: mechanism and surgical management. Ann Thorac Surg. 2003;76:1471-6.

30. Suzuki T, Isselbacher EM, Nienaber CA, Pyeritz RE, Eagle KA, Tsai TT, et al IRAD Investigators. Type-selective benefits of medications in treatment of acute aortic dissection (from the International Registry of Acute Aortic Dissection [IRAD]). Am J Cardiol. 2012;109:122-7.

31. Melby SJ, Zierer A, Damiano RJ Jr, Moon MR. Importance of blood pressure control after repair of acute type a aortic dissection: 25-year follow-up in $252 \mathrm{pa}-$ tients. J Clin Hypertens (Greenwich). 2013;15:63-8.

32. Brooke BS, Habashi JP, Judge DP, Patel N, Loeys B, Dietz HC III. Angiotensin II blockade and aortic-root dilation in Marfan's syndrome. N Engl J Med. 2008; 358:2787-95.

33. Groenink M, den Hartog AW, Franken R, Radonic T, de Waard V, Timmermans J, et al. Losartan reduces aortic dilatation rate in adults with Marfan syndrome: a randomized controlled trial. Eur Heart J. 2013;34:3491-500.

34. Geirsson A, Bavaria JE, Swarr D, Keane MG, Woo YJ, Szeto WY, et al. Fate of the residual distal and proximal aorta after acute type a dissection repair using a contemporary surgical reconstruction algorithm. Ann Thorac Surg. 2007;84:1955-64.

35. Huynh TT, Starr JE. Diseases of the thoracic aorta in women. J Vasc Surg. 2013; 57:11S-7S.

Key Words: aorta, aortic dissection, aortic surgery, sex, surgery

\title{
EDITORIAL COMMENTARY
}

\section{Gender differences in patients undergoing surgery for acute type $A$ aortic dissection: Is there really a glass ceiling?}

\author{
Alan Speir, MD
}

See related article on pages 581-7.

The impact of gender on outcomes has been incompletely studied across the spectrum of cardiac surgery. Among patients presenting for isolated coronary bypass grafting, women have been shown to have higher mortality according to meta-analysis at short-term, mid-term, and long-term

From Cardiac, Vascular, Thoracic Surgery Associates, Falls Church, Va Disclosures: Author has nothing to disclose with regard to commercial support. Received for publication June 15, 2015; accepted for publication June 17, 2015; available ahead of print July 17, 2015

Address for reprints: Alan Speir, MD, CVTSA, 2921 Telestar Ct, Falls Church, VA 22042 (E-mail: Aspeir1@gmail.com).

J Thorac Cardiovasc Surg 2015;150:587-8 0022-5223/\$36.00

Copyright (C) 2015 by The American Association for Thoracic Surgery http://dx.doi.org/10.1016/j.jtcvs.2015.06.038 relative to their male counterparts. ${ }^{1}$ The true influence of gender on surgical outcomes in patients with acute type $\mathrm{A}$ aortic dissection, however, has remained poorly defined.

In this article published in the current issue of the Journal, Fukui and colleagues $^{2}$ have attempted to analyze the influence of gender on the results of operative repair for acute

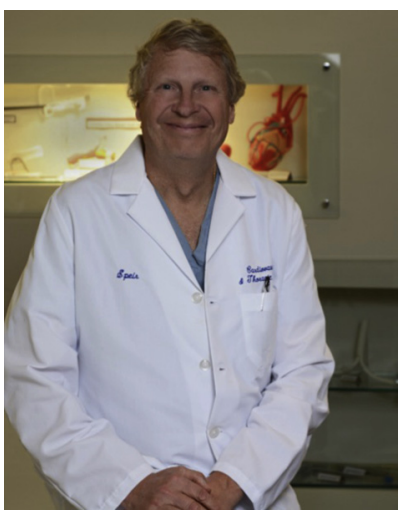
type A aortic dissection.

The primary end point of their evaluation of 504 patients during a 7-year period from a single institution by 4 surgeons who used uniform operative techniques was operative mortality, with secondary end points being late reoperation and late mortality. 
TABLE E1. Operative mortality in older age groups

\begin{tabular}{lclr}
\hline & Female & \multicolumn{1}{c}{ Male } & $\boldsymbol{P}$ value \\
\hline $70-75 \mathrm{y}$ & $7 / 63(11.1 \%)$ & $0 / 15(0 \%)$ & .3349 \\
$76-80 \mathrm{y}$ & $2 / 56(3.6 \%)$ & $1 / 31(3.2 \%)$ & $>.9999$ \\
$>80 \mathrm{y}$ & $0 / 36(0 \%)$ & $2 / 17(11.8 \%)$ & .0987 \\
All & $9 / 155(5.8 \%)$ & $3 / 63(4.8 \%)$ & $>.9999$ \\
\hline
\end{tabular}

